4. The general trend has been south, south-east, and southwest, but frequently deflected east and west by ranges and preexisting valleys. The great Flathead glacier west of $114^{\circ}$ shows a length of 150 miles from boundary. Along a line 150 miles south of boundary, which rapidly swings to the north as we go westward, the lower limits (moraines) of this series of glaciers is evident. To the south of these the glaciers have had a northerly trend, forming a series of valleys running worth and south. Short glaciers, radiating from local heights, as at Libby, and Missoula and various other places, were common. Some of these have no doubt been persistent for some time since the glacial period proper.

5. With the recession of the glaciers the lakes were drained to the west.

6. Existing glacial lakes are four or five in number. They are rock-basins eroded no doubt greatly before the glacial period. In nearly all cases they are dammed by terminal moraines.

7. The area touched upon is 300 miles (E. and W.) by 100-150 miles (N. and S.). The fall being to the west and south as noted; on the map it may be found from the 49th parallel on the north to the 47th on the south, from the Rockies (main range on east) to Idaho boundary-line.

8. Terraced valleys of much interest occur, but to which no detailed study has been given.

\title{
THE SHRINKAGE OF LEAVES.
}

$$
\text { BY E. E. BOGUE. }
$$

Probably every maker of botanical specimens has observed that the leaves when dry are smaller than when fresh. The wish to know how much the shrinkage might be led to the following measurements. The leaves were measured before they had wilted, and after they were perfectly dry.

The longest dimensions were taken in each case. The width or dimension across the midrib is first given in each case; the first column shows the measurements when fresh, and the second column the measurements when dry. All measurements are given in inches and parts of an inch.

Scarlet Oak (Quercus coccinea).

\section{Fresh.}

$7 \frac{3}{8} \times 12 \frac{1}{2}$

$6 \frac{1}{8} \times 11 \frac{1}{2}$

$65 \times 12 \frac{1}{2}$

$61 \times 12$

Arisæma triphyllum (Indian Turnip).

$$
\begin{aligned}
& 4 \frac{13}{16} \times 9 \\
& 5_{\frac{1}{4}} \times 8 \frac{8}{4} \\
& 4 \frac{1}{2} \times 7 \frac{8}{4} \\
& 4 \frac{8}{4} \times 7^{\frac{3}{16}} \\
& 5_{\frac{3}{16}}^{\frac{3}{6}} \times 7_{\frac{1}{2}}
\end{aligned}
$$

Dry.

$7 \frac{36}{16} \times 12_{16}^{5}$

$6 \times 11 \frac{8}{8}$

$699 \times 12 \frac{7}{16}$

$6 \frac{1}{8} \times 11 \frac{13}{16}$

$$
\begin{aligned}
& 4 \frac{3}{4} \times 9 \\
& 5 \frac{1}{4} \times 8 \frac{5}{16} \\
& 4 \frac{1}{2} \times 7 \frac{1}{2} \\
& 4 \frac{11}{16} \times 7 \frac{1}{6} \\
& 5 \frac{1}{5} \times 7 \frac{1}{2}
\end{aligned}
$$

Asimina triloba (Common Papaw).

$$
\begin{aligned}
& 4 \frac{7}{8} \times 125 \\
& 47 \times 13 \\
& 3 \frac{7}{8} \times 10 \frac{7}{8} \\
& 4 \frac{7}{16} \times 12 \\
& 5 \times 13 \frac{7}{8}
\end{aligned}
$$

$4 \frac{3}{8} \times 12 \frac{5}{8}$

$4 \frac{1}{4} \times 12 \frac{7}{8}$

$3 \frac{13}{16} \times 10_{\frac{9}{16}}^{9}$

$4 \times 11 \frac{7}{8}$

$4 \frac{7}{8} \times 13 \frac{3}{4}$

Arctium Lappa (Burdock)

$$
\begin{gathered}
9 \frac{5}{5} \times 15 \frac{8}{4} \\
11 \frac{5}{16} \times 17 \frac{7}{16} \\
9 \frac{1}{2} \times 14 \frac{8}{4}
\end{gathered}
$$

$9 \frac{1}{2} \times 15 \frac{8}{4}$

$11 \times 17 \frac{1}{4}$

$8 \frac{7}{8} \times 14 \frac{7}{16}$

\begin{tabular}{|c|c|c|}
\hline 7 & $\times 7$ & $6 \frac{1}{4}$ \\
\hline & $\times 8 \frac{3}{4}$ & 9 \\
\hline & $\times 7 \frac{3}{4}$ & $7 \frac{1}{2}$ \\
\hline 14 & $\times 14$ & 13 \\
\hline & $\times 10 \frac{1}{2}$ & $10 \frac{8}{8}$ \\
\hline
\end{tabular}

Asclepias cornuti (Milkweed).

$$
\begin{aligned}
& 4 \frac{1}{2} \times 7 \frac{15}{16} \\
& 4 \frac{1}{2} \times 9 \frac{1}{4} \\
& 4 \frac{1}{2} \times 9_{13}^{3} \\
& 4 \frac{1}{8} \times 9_{16}^{1} \\
& 3 \frac{1}{16} \times 8
\end{aligned}
$$

\begin{tabular}{|c|c|}
\hline $11 \frac{15}{1} \frac{5}{6} \times 12 \frac{1}{2}$ & $\times 11 \frac{1}{7} \frac{5}{6}$ \\
\hline $13 \frac{1}{2} \times 14 \frac{3}{8}$ & $\times 13 \frac{7}{8}$ \\
\hline $12 \times 121$ & $\times 118$ \\
\hline $12 \frac{8}{4} \times 13^{5} 5$ & $12 \frac{1}{2} \times 12 \frac{8}{4}$ \\
\hline $121 \times 124$ & $11_{18}^{1 \frac{3}{6}} \times 11 \frac{7}{8}$ \\
\hline $9_{16}^{\frac{1}{16}} \times 9 \frac{1}{2}$ & $9 \times 9 \frac{1}{16}$ \\
\hline
\end{tabular}

Acer saccharinum var. nigrum (Sugar Maple).

$$
\begin{array}{ll}
5 \frac{7}{8} \times 5 \frac{1}{16} & 5 \frac{8}{4} \times 5 \\
6 \frac{11}{16} \times 5 \frac{7}{8} & 6 \frac{5}{8} \times 5 \frac{13}{16} \\
7 \frac{7}{8} \times 5 \frac{7}{16} & 7 \frac{9}{4} \times 5 \frac{8}{8} \\
7 \frac{5}{8} \times 5 \frac{7}{8} & 7 \frac{1}{4} \times 5 \frac{13}{16} \\
6_{\frac{7}{16}}^{7} \times 5 \frac{1}{4} & 6 \frac{8}{8} \times 5 \frac{1}{4}
\end{array}
$$

Abutilon avicennæ (Velvet-Leaf).

$$
\begin{aligned}
& 8 \frac{5}{16} \times 8 \frac{5}{16} \\
& 9 \times 9 \frac{5}{8} \\
& 8 \times 8 \\
& 3 \times 3 \frac{1}{5} \\
& 9 \frac{3}{16} \times 8 \frac{7}{8} \\
& 9 \times 9 \frac{1}{4} \\
& 8 \frac{1}{2} \times 8 \frac{1}{2}
\end{aligned}
$$

$84 \quad \times 81$

$8 \frac{7}{8} \times 9 \frac{1}{2}$

$7 \frac{7}{8} \times 7 \frac{13}{16}$

$2 \frac{1}{16} \times 3$

$9 \times 8$

$8 \times 9$

$8 \frac{7}{16} \times 8 \frac{1}{2}$

Rumex obtusifolius (Bitter Dock).

$$
\begin{array}{ll}
5 \times 11 \frac{1}{4} & 4 \frac{7}{8} \times 11 \\
4 \frac{11}{16} \times 8 \frac{1}{2} & 4 \frac{7}{16} \times 8 \frac{1}{8}
\end{array}
$$

Platanus occidentalis (Sycamore).

$$
\begin{aligned}
& 8 \frac{1}{4} \times 6 \frac{1}{2} \\
& 87 \times 7 \frac{1}{8} \\
& 9 \frac{1}{4} \times 6 \frac{1}{2} \\
& 7 \frac{5}{8} \times 6 \frac{1}{16}
\end{aligned}
$$

Nymphæa odorata (Sweet-scented Water-Lily).

Nelumbo lutea (Yellow Nelumbo).

The leaves were pressed enough to keep them from wrinkling. A piece the size of a mounting-sheet $\left(11 \frac{1}{2} \times 16 \frac{1}{2}\right)$ was cut from a leaf of the Nelumbo, and was found to decrease from that size to $11 \times 15_{\frac{1}{16}}$. It will be seen that the least shrinkage was in the Indian turnip (the measurements here referring to leaflets), and the greatest shrinkage in the water-lily. Petioles of the sugar-maple were measured and ranged from $2 \frac{8}{4}$ to $4 \frac{7}{16}$ in length, but were shortened by drying, if at all, less than $\frac{1}{16}$.

It will be noticed that in the velvet leaf the small immature one decreased more even than the largest one.

Ohlo State Unlversity, Sept. 10.

\section{LETTERS TO THE EDITOR.}

\section{Pre-Aino Race in Japan.}

I MUCH regret that Prosessor Morse should think that I have intentionally misrepresented or carelessly disregarded his views concerning the pre-Aino occupancy of Japan, as he rather vigorously maintains in Science of Sept. 9. It can scarcely be said that I have claimed for myself the discovery that there was a race of people in Japan before the Ainos. The most I have endeavored to show is the possibility, - I do not even go so far.as to suggest the probability, - that the pre-Aino inhabitants of Japan may have been the people who dug the pits in Yezo.

As regards the Aino occupancy of Japan, Professor Morse will find that the "historical records" of the country, which he mentions, have not been disregarded in my article, and, in fact, the evidences of the shell heaps are, to my mind, the least convincing of any, until the fact of the Aino origin of them is established. It is the historical evidence, the distribution of geographical placenames, and, last but not least, Japanese tradition, which are at present the strongest evidences in this connection.

An author may be criticised for sins of omission, and even for 